\title{
“¿Por qué me tratan así? No quiero ir, prefiero no ir..." \\ Experiencias escolares de estudiantes de origen boliviano en Argentina
}

\section{María Eugenia Taruselli ${ }^{1}$}

\author{
1 Instituto de Lingüística, Facultad de Filosofía y Letras. Universidad de Buenos Aires. Ciudad Autónoma \\ de Buenos Aires, Argentina. \\ ORCiD: 0000-0002-0604-0834 \\ Correo electrónico: me.taruselli@gmail.com
}

Recibido:

mayo de 2019

Aceptado:

febrero de 2020

doi: $10.34096 /$ runa.v41i1.6267

\section{Resumen}

A pesar de que actualmente el paradigma escolar propone aceptar y respetar la diversidad cultural, puertas adentro continúan dándose situaciones solapadas, así como también explícitas y violentas, de marginalización y segregación. Esto se da en el marco de una sociedad que aún se piensa blanca y europea y en la cual los inmigrantes de países latinoamericanos son vistos como grupos raciales inferiores. Teniendo en cuenta este contexto, el artículo se propone analizar parte de las experiencias escolares de niños/as y jóvenes de origen boliviano que asisten a escuelas rurales del conurbano bonaerense. Para este fin, desde una perspectiva etnográfica, los materiales recopilados durante el trabajo de campo serán analizados retomando reflexiones teóricas de autores/ as de la antropología de la educación en contextos interculturales, haciendo especial referencia a las poblaciones migrantes.

\section{"Why do they treat me like this? I do not want to go, I prefer not to go..." School experiences of student of Bolivian origin in Argentina}

\begin{abstract}
Although the school paradigm currently proposes to accept and respect cultural diversity, discrete situations, as well as explicit and violent ones of marginalization and segregation, continue to occur. This happens in a society that is still considered white and european and in which immigrants from Latin American countries are seen as lower racial groups. In this context, the present article propose to analyze school experiences of children and y Bolivian young people who assist rural schools in the Buenos Aires suburbs, in order to try
\end{abstract}

\section{Palavras-chave}

Experiencias escolares; Estudiantes de origen boliviano; Migraciones; Escuela; Discriminación

\section{Key words}

School experiences; Students of Bolivian origin; Migrations; School; Discrimination 
to elucidate under what conditions they are. To this purpose, from an ethnographic perspective, data collected during the field research will be analyzed by taking up theoretical reflections from anthropology of education authors in intercultural contexts, making special reference in migrant populations.

\section{"Por quê me tratam assim? Não quero ir, prefiro não ir!" Experiências escolares de estudantes de origem boliviana na Argentina}

\section{Resumo}

Palavras-chave

Experiências escolares; Estudantes de origem boliviana; Migrações; Escola; Discriminação
Apesar do fato de que o modelo escolar, atualmente, se propor a aceitar e a respeitar a diversidade cultural, as situações de violência explícitas e silenciosas de marginalização e segregação continuam sendo parte da rotina dentro das escolas. Isto se dá no marco de uma sociedade eurocêntrica na qual os imigrantes dos países da América Latina são encarados como grupos raciais inferiores. Dentro deste contexto, o presente artigo se propõe a analisar parte das experiências escolares de crianças e jovens de origem boliviana que frequentam escolas rurais da província de Buenos. Para tanto, a partir de uma perspectiva etnográfica, os materiais coletados durante o trabalho de campo serão analisados a partir de reflexões teóricas de autores da antropologia da educação em contextos interculturais, fazendo especial referência às populações migrantes.

\section{Introducción}

A lo largo de la historia, la Argentina se pensó y construyó a sí misma en un vínculo estrecho con la población migrante. Este vínculo no siempre fue igual, sino que fue mutando a lo largo del tiempo, así como la percepción que se tenía sobre las personas que llegaban al país, quienes fueron clasificadas al mismo tiempo como migrantes deseados y no deseados según las supuestas cualidades intrínsecas a su nacionalidad de origen. La escuela, institución por excelencia encargada de difundir la identidad nacional entre los/as niños/as y jóvenes, también fue transformándose, al igual que sus estrategias y paradigmas de inclusión de los "Otros".

Desde los inicios del Estado-nación, la migración europea fue vista como portadora de modernización y civilización; en tal sentido, aquella era deseada e incentivada. Hacia fines del siglo XIX, con la llamada inmigración de masas proveniente de dicho continente y ante la necesaria afirmación de una identidad nacional (caracterizada por un pueblo asociado a un territorio y portador de una única lengua y cultura) (Hecht, 2007), se crea en Argentina el sistema educativo moderno. Influenciado por el positivismo y evolucionismo de la época, dicho sistema tuvo como objetivo principal eliminar los aportes de aquellas culturas consideradas bárbaras y simples (Sinisi, 1999), las cuales estaban representadas por los indígenas del territorio. Las políticas homogeneizadoras en educación, características de ese periodo, contribuyeron a la conformación de aquella identidad nacional y, en el marco "igualador" que proponía la Ley de Educación № 1420 (1884), se negaron las especificidades lingüísticas y culturales (Hecht, 2007, 2013). Para Sarmiento, la escuela primaria obligatoria 
sería la encargada de fundir las diferencias y sentar las características de una nueva sociedad argentina (Beheran, 2012).

Así, desde la conformación del Estado-nación, se construyó un relato a partir del cual la población argentina fue pensada como el resultado de un "crisol de razas" europeas; los argentinos, según ese relato, descendían de los barcos y carecían de sangre indígena (Grimson, 2006). Es así que, además de invisibilizar la diversidad existente -ya que se planteó y se continúa planteando una fusión de culturas-, se seleccionó estratégicamente la migración conformadora de la población, y se eliminó de la supuesta matriz fundacional de la identidad nacional a los grupos migrantes de países vecinos, entre otros. Este hecho se debió a que estos últimos se relacionaron de forma directa con la población indígena que el Estado en su conformación intentó exterminar tanto física como culturalmente. Es por este motivo que aún en la actualidad continúan siendo definidos como símbolo del atraso y subdesarrollo del que Argentina emergió gracias a los inmigrantes transatlánticos, quienes permitieron civilizar la nación a fines del siglo XIX (Gavazzo, 2013).

Si bien las leyes, así como las políticas de acogida y contención para la población migrante fueron transformándose a lo largo del tiempo de forma positiva y adquirieron una mirada basada en los derechos humanos, las prácticas discriminatorias con respecto a las personas provenientes de países latinoamericanos continúan en pie. Esta situación se vio claramente agravada con el gobierno macrista de corte neoliberal (2015-2019), el cual, gracias a sus discursos y medidas xenófobas (como el decreto de necesidad y urgencia N.․ 70/2017), construyeron a los/as inmigrantes de países vecinos (al igual que en los años noventa) como la causa de gran parte de los males del país: desocupación, inseguridad, sobrecarga en el sistema de salud, entre otras cuestiones.

En cuanto al plano escolar, la Ley Nacional de Educación N. 26.206 (2006) plantea la importancia de valorar la diversidad cultural e incorpora distintos saberes y formas de estar, ver e interpretar el mundo; y establece, entre otras, la Modalidad de Educación Intercultural Bilingüe (en adelante, EIB). De esta manera, se propone abandonar la visión homogeneizante que planteaba "normalizar" a los/as estudiantes imponiendo el abandono de sus prácticas culturales para poder incorporarse a la nación argentina (Pineau, 1997 en Thisted, 2014). No obstante, si bien en el desarrollo del texto de la ley se plantea en reiteradas oportunidades el "respeto por la diversidad cultural" como un valor a adoptar desde la escuela, esta idea, al igual que la Modalidad de EIB, se asocia directamente con los pueblos indígenas dejando así de lado a la población migrante (Taruselli, 2017). En contrapartida, en la Ley de Educación de la Provincia de Buenos Aires N. 13.688 (2007), sí se incluye a los/as migrantes como posibles destinatarios de la modalidad de EIB, y sostiene su derecho a recibir una educación que ayude a preservar y recrear sus pautas culturales, sus lenguas e identidades.

Ahora bien, en este contexto social y educativo, sabiendo que la escuela se convierte en uno de los primeros espacios a los que, en general, se acercan los/ as niños/as y jóvenes inmigrantes (Beheran, 2012) y que la escolaridad conforma una parte fundamental en sus experiencias, que influye tanto en su formación intelectual como en sus relaciones e identificaciones (Gavazzo, Beheran y Novaro, 2014), es que me propongo llevar adelante este trabajo. Este se enmarca en los avances de mi proyecto de doctorado en Ciencias Antropológicas, el cual se lleva a cabo en tres escuelas rurales del conurbano bonaerense (jardín, primaria y secundaria) de una misma comunidad. Estas instituciones se 
1. Me refiero a estudiantes cuyas familias no se reconocen como migrantes ni indígenas.

2. Me refiero tanto a niños, niñas y jóvenes migrantes bolivianos/ as como argentinos/as hijos/as de migrantes bolivianos/as.

3. En total, se realizaron 116 visitas al campo. caracterizan por su población estudiantil, la cual adscribe a múltiples identificaciones étnico-nacionales (migrantes e hijos/as de migrantes bolivianos/as y paraguayos/as, indígenas tobas/qom y criollos/as) ${ }^{1}$.

Para esta oportunidad, el artículo se propone describir y analizar parte de las experiencias escolares de los/as niños/as y jóvenes de origen boliviano ${ }^{2}$ que asisten a estas instituciones escolares, en el marco de un sistema educativo que se presenta como democrático e inclusivo con respecto a la diversidad y de una sociedad que sigue creyéndose blanca y "descendiente de los barcos".

Para lograr dicho fin, la metodología de investigación se basó en un abordaje antropológico desde un enfoque etnográfico, con el fin de documentar lo no documentado de la realidad social (Rockwell, 2009). Ya que los/as niños/as y jóvenes de esta investigación son considerados agentes sociales que participan y otorgan sentidos a los procesos en los que están involucrados (así como a sus propias historias), y cuyo análisis es válido y necesario para la investigación social (García Palacios y Hecht, 2010), serán los/as principales interlocutores en este artículo. De esta manera, la noción de "simetría ética" -la cual postula que la relación ética del investigador con sus informantes debe ser idéntica, ya sean estos adultos o niños/as- se tornó fundamental (Christensen y Prout, 2002). El trabajo despliega entonces un corpus conformado por fragmentos de charlas informales y entrevistas, así como por registros tomados durante la observación participante en distintos espacios escolares. ${ }^{3}$ Esta última técnica "es clave, en tanto gran parte de la acción social no se explicita como discurso, particularmente en el campo de la niñez" (Szulc et al., 2009, p. 3). Finalmente, para la construcción y análisis de estos datos, retomaré las reflexiones teóricas de autores/as de la antropología de la educación en contextos interculturales.

\section{En la escuela... ¿Bajo qué condiciones?}

En Argentina, si bien durante los últimos años se verifica un constante incremento de la cobertura educativa, ya que se amplió el universo de sectores que acceden a la escuela, las desigualdades en el sistema continúan en diversos planos (Kessler, 2014) y según la población considerada. Una de ellas es la población boliviana, entre la cual se constata una disminución considerable de la matrícula de niño/as en el paso de la escuela primaria a la secundaria (Diez y Novaro, 2012; Groisman y Hendel, 2017). Este hecho se observa claramente en el contexto estudiado, en el cual el desgranamiento estudiantil en general, pero sobre todo el de jóvenes de origen boliviano, es llamativo.

Ante este panorama, Diez y Novaro (2007) se preguntan cómo se explica la reducción de estos/as estudiantes en el pasaje de un nivel a otro y si estar dentro de la escuela es en sí mismo un indicador de no exclusión o de no discriminación. Así, las autoras plantean que existen diversas variables, como la socioeconómica, que pueden influir en la discontinuidad de la escolaridad de estos/as estudiantes; sin embargo, sostienen que es necesario profundizar en ciertos factores internos a ella, los cuales son tan importantes como los externos (Diez y Novaro, 2007, 2012). En este sentido, en ocasiones la escuela incluye excluyendo a partir de lo que se llaman las "formas más sutiles de discriminación", las que entran en tensión con los discursos y propuestas democratizadoras que el sistema educativo propone (Diez y Novaro, 2012). En consecuencia, muchos/as niños/as y jóvenes producen su experiencia escolar 
cotidiana de forma cercana a la segregación, la discriminación y la marginalización, y se constituyen así como "los excluidos de adentro" (Sinisi, 2010). Novaro llama, a este tipo de inclusión, inclusión subordinada (Novaro, 2016), la cual podría derivar en trayectorias escolares continuas pero no completas o trayectorias signadas por la discontinuidad (Terigi, 2010).

Este artículo problematiza la idea instalada de acuerdo con la cual la sola inclusión y permanencia de los/as niños/as y jóvenes en las instituciones educativas es beneficiosa per se (Sinisi, 2010) y se pregunta en qué términos o a expensas de qué, los/as estudiantes de origen boliviano se encuentran en la escuela argentina.

\section{Nacionalismo y construcciones identitarias en la escuela}

Los/as jóvenes bolivianos/as del barrio transitan experiencias migratorias -ya sean propias o de miembros de su familia- desde muy temprana edad. El continuo fluir entre países que se da generalmente, obliga a muchos/as a cursar sus estudios en diferentes instituciones escolares, dentro de cada una de las cuales cambian no solo los contenidos sino las dinámicas. En este marco, una situación que se da en reiteradas oportunidades es el olvido en Bolivia de documentos y certificados que avalan el año en que se encontraban cursando, así como las calificaciones. Si bien la Ley N. 25.871 (2003) sostiene que la inserción escolar debe ser inmediata aunque la documentación no esté completa o falte su legalización, esto no se cumple siempre, lo que vulnera gravemente el derecho a la educación, ya que se interrumpe la continuidad de sus estudios en el país de acogida y en ocasiones se resigna el ingreso al sistema educativo:

\begin{abstract}
Mientras esperábamos que los/as niños/as salgan del jardín, una joven mamá boliviana me contaba apenada que su hermano menor de 15 años, quien había llegado hace poco, no había podido ingresar a la secundaria. En la institución le dijeron que si no tenía un certificado que avale en qué año de la escuela se encontraba en Bolivia no lo podían inscribir. No obstante, le ofrecían otra opción: podía ser anotado pero "bajado"4 dos cursos en relación al que le correspondía, comenzando así en la escuela primaria. El joven se rehusó a esta propuesta porque “es grande y no quería estar entre los chiquitos". Así que, como no pudo entrar a la escuela del barrio, se puso a trabajar con sus hermanos más grandes. (Nota de campo, marzo de 2016)
\end{abstract}

Diez y Novaro (2014) sostienen que en Argentina existen sobre el sistema educativo boliviano muchas imágenes instaladas y muy poca información, en ocasiones con la presunción de que se basa en parámetros absolutamente distintos al nuestro. En esta línea, el fragmento seleccionado expone, además del incumplimiento de la normativa vigente, los prejuicios con los cuales la institución o ciertos directivos se manejan a la hora de dar ingreso a estos/as estudiantes. ¿Por qué el joven no puede ingresar a la secundaria por falta de documentación pero sí lo puede hacer a la primaria? ¿por qué se propone su inscripción dos cursos por debajo del que le corresponde? Así, queda clara la desigualdad de oportunidades producto de las relaciones de poder a las cuales muchos/as niños/as y jóvenes extranjeros/as, junto a sus familias, se ven sometidos/as.

Es necesario decir que estas familias representan la mitad del barrio donde se encuentran las escuelas, y se vinculan entre sí a través de relaciones de parentesco y/o fuertes lazos de amistad y compadrazgo. Asimismo, un gran
4. El "entrecomillado" en las notas de campo y fragmentos de entrevistas indican citas textuales de las personas. 
5. Los nombres de las personas han sido modificados para resguardar sus identidades. número de chicos y chicas que migraron a la Argentina de muy pequeños/as (algunos/as de bebés), van juntos/as a la escuela desde el jardín de infantes o la primaria. Por lo tanto, existen cursos que presentan varios/as estudiantes de origen boliviano, y en ocasiones son la mayoría. Ahora bien, a diferencia de otras investigaciones en las cuales se analizaron en el contexto escolar situaciones, representaciones y discursos referidos al silencio/silenciamiento (Diez y Novaro 2007; Novaro, Borton, Diez y Hecht 2008; y Novaro 2014) y vergüenza (Martínez, 2011) de estos/as estudiantes; observé que durante el transcurso por el jardín y la primaria, en su mayoría, los/as niños/as hablaban de Bolivia con entusiasmo, en diversas situaciones de clase y frente a distintas personas; pocas fueron las ocasiones en las cuales detecté vergüenza, silencio generalizado u ocultamiento del origen propio o familiar (Taruselli, 2018).

Primaria, 6to. grado. La maestra les trae a los/as estudiantes fotocopias con la letra de la canción Encuentro en Cajamarca para ver si reconocen algunas palabras en quechua [...] Luego de analizarla y de que los/as chicos/as reconocieron varias, la maestra pone la canción en su netbook para que la escuchen y canten. Cuando termina la canción les pregunta: “¿El que canta a quién representa?”. Los/as estudiantes contestan: "A Dios”, “A Bolivia”, "Es un boliviano”, "Se nota (que es boliviano) por cómo canta y los instrumentos parecen de Bolivia”. La maestra les pregunta: “¿De Bolivia solo?”. Responden que no, que también de Argentina, Perú, de Santa Cruz. [...] Luego les hace escuchar otra canción, Amutuy. [...] Ella les dice que van a volver a escuchar las canciones, entonces Marta 5 le pide: “iLa que es de Bolivia, seño!”. Héctor replica: “No es de Bolivia, el que canta es argentino y los instrumentos son de Bolivia”. Si bien la maestra incitaba a todos/as a participar, los/as únicos/as que lo hicieron fueron los/as de origen boliviano. (Nota de campo, octubre de 2017)

No obstante, a pesar de conformar un número importante tanto en la matrícula escolar como en el barrio, a medida que estos niños y niñas van creciendo, dejan de hablar de forma espontánea y con entusiasmo sobre sus orígenes en el ámbito escolar, y seleccionan estratégicamente el momento y con quiénes hacerlo (Taruselli, 2018). En coincidencia, Beheran (2008) detectó, entre estudiantes de origen boliviano de primer año de la secundaria, situaciones de invisibilización u ocultamiento -dentro de la escuela- con respecto a sus trayectorias migratorias y orígenes nacionales. Asimismo, muchos/as niños/as que en la escuela primaria expresaron en varias oportunidades sentirse "mitad argentino/a, mitad boliviano/a" (Taruselli, 2018), al ingresar a la escuela secundaria comenzaron a relativizar sus afirmaciones. A continuación, observemos cómo los mismos niños que en la primaria se autopercibieron como "boliviano" y "mitad y mitad", al pasar a la secundaria se identifican de otra forma o ya no se expresan con la misma seguridad respecto de sus dichos anteriores

Clase de computación, 6to. grado. Los/as chicos/as están divididos en grupos y tienen que buscar información sobre países de América. Me siento con unos niños (bolivianos e hijos de bolivianos) que deben investigar sobre Bolivia, México, Colombia y Panamá. [...] me muestran que ya dibujaron la bandera boliviana. Les pregunto si saben qué significan los colores de la misma e inmediatamente, Damián me contesta mientras busca cosas en Internet: "rojo por la sangre boliviana, amarillo por el oro que todavía no encuentran y verde por el pasto". Me asombro de la ligereza con la que dice el significado de cada color y le pregunto cómo sabe eso. A lo cual me contesta: "yo soy boliviano" y, enseguida, Héctor que estaba a su lado, me dice: "yo soy mitad, porque soy argentino pero mis papás son bolivianos" y agrega por Luis: “él también es mitad”. Luis asiente. (Nota de campo, junio de 2017) 
Prácticas del Lenguaje, $1^{\circ}$ año de la secundaria. La actividad consiste en armar el árbol genealógico de la familia. [...] Me siento en el grupo de Luis, Héctor y Damián para charlar y ver cómo están completando los círculos en cartulina donde deben escribir sus datos. Observo que Damián puso como nacionalidad "argentino". Me extraña porque él me había dicho el año pasado que era boliviano (ver nota anterior). Entonces le digo, “Damián, yo pensé que eras boliviano...”. Él me contesta que no, que nació en Argentina. Continuamos charlando, entonces se acerca Rosita (hija de bolivianos) a charlar con nosotros y, sorprendida al ver el círculo de Luis con los datos que completó, se lo arrebata y le dice:

Rosita:- “iLuis! i¿Eres de Argentina?!

Luis:- ¡Sí! (le saca rápidamente el círculo escondiéndolo entre sus brazos apoyados en la mesa).

Rosita:- ¿No eres de Bolivia? (insistiendo sorprendida).

Luis:- ¡No! (ofuscado).

Rosita:- ¡Si vos naciste en Bolivia!...”

Rosita me mira desconcertada y, ante la falta de respuesta de Luis que no la mira, continúa hablando conmigo de otra cosa. (Nota de campo, junio 2018)

Prácticas del lenguaje, $1^{\circ}$ año de la secundaria. Continúan con la clase anterior del árbol genealógico. Me siento otra vez con Luis, Damián, Héctor y Santiago [...] Les pregunto:

Investigadora:- “¿Se acuerdan que en una entrevistas que les hice, ustedes me contaron que se sentían mitad argentino mitad boliviano? (asienten sin hablar)

Héctor:- Sí... yo un poco... (relativizando lo que me dijo en varias oportunidades, ya no tan seguro y tímido)

Investigadora:- ¿No pueden poner eso en este trabajo?

Héctor:- Hay que poner solo la nacionalidad." (Nota de campo, junio 2018)

Vemos cómo la forma en la que las personas se identifican -y son identificadas por otros- puede variar mucho de un contexto a otro; lo que implica que la identificación del yo y del otro son fundamentalmente situacionales y contextuales (Brubaker y Cooper, 2005). Por lo tanto, es desde los encuentros intersubjetivos que se elaboran los modos de ser y estar en el mundo; los cuales pueden ser de carácter muy distinto, como los que se dan en el ámbito escolar (Rivas Flores, Leita Méndez, Cortés González, Márquez García y Padua Arcos, 2010). Así, a través de estas notas de campo, podemos observar cómo las estrategias de autopresentación pueden ser heterogéneas e ir de la negación hasta la reflexión sobre la propia identidad y el reconocimiento del origen (Gavazzo, 2013). En este sentido, las identificaciones de estos/as estudiantes se presentan complejas y contradictorias, ya que expresan la coexistencia de valoraciones del país de origen con percepciones negativas asociadas a él (Diez y Novaro, 2007).

De la misma manera, queda expuesta la mirada que la escuela tiene sobre la existencia de diferencias culturales de base etnonacional, las cuales son 
concebidas como yuxtapuestas en el espacio social y en el universo mentalafectivo de los/as chicos/as de origen extranjero (Franzé Mundanó, 2002). Esta visión dualista de las culturas los/as imagina ante una irremediable opción entre la cultura de origen y la cultura de destino, y los/as enajena así de sus experiencias polivalentes, en las que se conjugan diversos referentes culturales y múltiples conflictos, en una construcción única de la identidad (Franzé Mundanó, 2002). Como sostiene Domenech (2014), para la escuela, la adscripción a una u otra categoría nacional se plantea en términos dicotómicos: se es boliviano/a o se es argentino/a.

Por otra parte, casos similares al expuesto en este trabajo han sido analizados por varios/as autores/as (Groisman y Hendel, 2017; Novaro, 2016; Mendiburu, Guitart y Badenas, 2010). En ellos, los/as estudiantes exponen una construcción sobre sus identificaciones nacionales que lejos se encuentra de aquella que históricamente planteaba la escuela, en la cual se asocia un pueblo con un territorio, una lengua y una cultura (Hecht, 2007). Así, pareciera que para ellos/as, ser o sentirse argentino/a y boliviano/a no es una contradicción o, por lo menos, no parecieran ser términos excluyentes uno del otro, como se postula desde el mandato escolar nacionalizador (Novaro, 2016), el cual se reactualiza constantemente y construye una clara oposición entre nativos y extranjeros (Diez, 2013).

Los Estados, por medio de diversas políticas educativas -entre otras de distinta categoría- promueven ciertas identidades y, al mismo tiempo, niegan o limitan otras (Díaz et al., 2009 en Diez, 2011). En este sentido, a pesar de la multiplicidad de identificaciones y sentidos de pertenencia que presentan estos/as niños/as y jóvenes, la escuela sigue sosteniendo la demanda de asimilación gracias al nacionalismo escolar (Gavazzo et al., 2014). De forma tal que es difícil observar identidades híbridas, múltiples o combinadas, como podrían ser argentino-boliviano y argenbol (Domenech, 2014). Todo esto se torna claro cuando pareciera que es imposible realizar una tarea en la cual se piense o exprese la nacionalidad como "mitad y mitad" o cuando se homogeneiza a los/as estudiantes mediante la jura a la bandera argentina, sin tener en cuenta la diversidad de orígenes ni de identificaciones presentes.

\section{Desmarcación y "dejar de ser" como estrategias de integración}

A pesar de que actualmente en la retórica de las políticas y programas socioeducativos se implementa la categoría de inclusión (en términos de derechos a una buena educación que incluya a los/as estudiantes en sus diferencias) en vez de integración (en términos de necesidades educativas especiales y déficit), no es común encontrar en los discursos cotidianos escolares referencias a las "prácticas de inclusión" (Sinisi, 2010). Ya sea que hablemos de inclusión o integración, en el contexto estudiado, cualquiera de las dos categorías difícilmente pueden ser asociadas a una educación que incluya a los/as estudiantes en sus diferencias. Estas parecen desaparecer o se intenta que desaparezcan (al menos ese es el deseo de algunos/as) y muchos/as docentes lo afirman al sostener que "son todos iguales".

Directivo:- "(en la escuela) Se trata la diversidad pero no la diversidad étnica [...] todo pareciera apuntar a la integración, pero desde la familia. Las familias lo que pretenden es que los hijos se integren. 
Investigadora:- ¿Y de qué forma?

Directivo:- Dejando la lengua original, las costumbres originales o pensás que las bolivianas jovencitas, estas chicas que estudian [...] ¿vas a ver alguna con el pibe en el hombro atado atrás? No. Eso lo van a conservar las viejas.

Investigadora:- ¿Y la escuela ante esto cómo responde?

Directivo:- ¿Cómo respondés vos? vos tenes que responder según los intereses de la comunidad. Vos no le podes imponer intereses. Vos no tenes ninguna posibilidad de imponerle un interés. El que no quiere... vos decis 'no pero ustedes son bolivianos, entonces ustedes..."” (Entrevista. Primaria, noviembre de 2016)

Investigadora:- “¿Con quién más charlan sobre Bolivia?

Judith:- Yo hablo con mi mamá pero [...] no le gusta que hable de Bolivia

Investigadora- ¿Por qué? a ver, contame...

Judith:- La idioma... viste como hablan en quechua. No me deja hablar. Por eso yo... yo... mi hermano y mi hermanita no hablamos en quechua porque no le gusta que hablemos.

\section{$[\ldots]$}

Investigadora:- ¿Y vos le preguntaste alguna vez a tu mamá por qué no quiere que aprendan quechua?

Judith:- No sé... mi hermano sabía hablar pero [...] era chiquitito y sabía hablar de castellano y de quechua. En dos idiomas. Y mi mamá dijo que un día le pegó y después se olvidó... y solo habla español. No le gusta que hablemos...

Investigadora:- ¿Y ustedes en sus casas, cómo es?

Laura:- Yo hablo así con mis hermanos. Cuando vine acá en mis siete, yo hablaba en quechua. Y mi papá me decía 'no hables acá porque si no... se te...'

Mariana:- Se te van a burlar...

Laura:- Se te van a burlar en la escuela. Aprendí a hablar y ahora hablo así. Yo en Bolivia a veces me ponía una pollera, iba a la escuela a veces así.

Investigadora:- ¿Qué pollera usabas?

Mariana:- Así como usan las cholitas..." (Entrevista a niñas bolivianas. 6to. grado, noviembre de 2017).

Pareciera que la integración al ámbito escolar es responsabilidad de los/as estudiantes y sus familias. Esta se daría, entre otras estrategias, en términos de abandono de lo propio, de la pérdida de ciertos "rasgos" y no a partir de la sumatoria o combinación con otros. En este punto, la escuela vuelve a adquirir (si es que alguna vez dejó de tenerlo) su carácter asimilacionista. Y vuelve a adquirirlo no solo activamente cuando les solicita a las familias, por ejemplo, que no le enseñen quechua a sus hijos/as "para que no se confundan"; sino cuando naturaliza, aprueba y acepta pasivamente la integración de los "Otros" 
a partir de su "dejar de ser": dejar de ser cholita, dejar de ser indio, dejar de ser boliviano. El razonamiento por el cual se sostiene que no se pueden imponer intereses a una comunidad que pretende integrarse dejando sus costumbres atrás es, por lo menos, simplista. En esta afirmación no se problematizan ciertas cuestiones tales como ¿en qué contexto histórico y social estas familias y sus hijos/as deciden dejar de lado su lengua y sus costumbres? ¿Estas decisiones son libres o se encuentran atravesadas por relaciones de poder y desigualdad? Definitivamente estas familias no alteran la realidad en la que viven para integrarse, sino que se transforman a sí mismas para poder adaptarse a ella. Se alteran a partir de la pérdida de lo propio para poder ser aceptados/as. Sin embargo, su "dejar de ser", o su intento, no es condición suficiente para lograrlo.

En este sentido, sucede algo sorprendente con la población boliviana en Argentina y es el hecho de que, a pesar de que muchos/as se esfuerzan en adaptarse al nuevo hogar y hasta utilizan diversas estrategias de desmarcación (que veremos más adelante), continúan sufriendo tratos hostiles y discriminación en diferentes ámbitos sociales. Uno de ellos es la escuela. En consecuencia, el modelo de adscripción étnica voluntaria, propuesto por Juliano (1987), no funciona como matriz de inserción o de integración social para los inmigrantes bolivianos; así, la ideología voluntarista del sentido de pertenencia y su correlato de una opción asimilacionista individual no configurarían una alternativa válida de inserción para esta población (Caggiano, 2005). Asimismo, los/as argentinos/as hijos/as de bolivianos/as no quedan exentos de estas prácticas, y en varias oportunidades serán vistos/as como bolivianos/as por otros/as argentinos/as y en ocasiones por sus familiares y hasta por ellos/ as mismos/as. Cuestión que quedó expuesta con la idea de sentirse "mitad y mitad" por tener sangre boliviana. En este sentido, Grimson (2006) señala que la categoría boliviano, entre otros usos sociales, es utilizada para nombrar no solo a las personas nacidas en Bolivia, sino también a sus hijos/as. Así, estos/ as serían argentinos/as en términos legales pero bolivianos/as en términos sociales (Grimson, 2006).

Ahora bien, ¿qué implica ser identificado/a como boliviano/a en la escuela?

Durante el trabajo de campo, pude presenciar algunas situaciones en las cuales se hicieron referencias negativas hacia el pueblo boliviano o se utilizó esta palabra de forma despectiva o como chiste. Estas situaciones solo las detecté en los últimos años de la escuela primaria y continuaron en la secundaria. Asimismo, en varias entrevistas que mantuve con niños/as, jóvenes y madres, surgió el tema de la discriminación y el racismo que sufren a diario:

Investigadora:- “¿Con quién hablan sobre Bolivia o Jujuy?

Ernesto:- Eh... no hablo de nada porque todos son discriminatorios acá.

Investigadora:- ¿Ah, sí? cuéntenme sobre eso... ¿qué te pasa a vos, Ernesto?

Ernesto:- Siempre me hacían bullying antes.

Investigadora:- ¿Por qué te hacían bullying? (hace un gesto como que no sabe el porqué)

Emiliano:- A mí también me hacían bullying 
Flavio:- iiAh!!... iientonces ya entendí: bullying-boliviano!!” (concluyendo mediante un juego de palabras). (Entrevista a niños argentinos de familia boliviana. 4to. grado, noviembre de 2017)

Roberta:- “[...] Por qué tanto quejan de mi hijo, me lo retan, me lo retan. Cuando tienen que soportar, a veces tu hijo también responde. [...] Humillan, humillan, humillan, entonces les quieren pegar, cualquier cosa ya quieren hacer. Entonces yo le hablé a la maestra y me decía 'el también, una palabra le dicen y ahí nomás lo quiere pegar. Ya quiere saltar, tu hijo también tiene que aguantar'[...]

Investigadora:- Digamos que él está sufriendo por la relación con los compañeros...

Roberta:- Sí, sí. ‘Boliviano', 'negro', cualquier cosa le tratan. Eso no le gusta a él. '¿Por qué me tratan así? no quiero ir, prefiero no ir' [...] 'me humillo, me humillo mami, ¿qué hago?'; 'vos también tienes que responder hijo, ¿por qué tanto tienes que humillarte?'. Hace un mes pasé llorando, nomás (por la escuela). Veo a sus compañeros, vienen del colegio y llegan al quiosco y compran. Mi hijo no llega, va con su papá al campo. [...] Cuando veo a sus compañeros me siento en mi lagrimeo porque mi hijo también puede estar aquí y no así”. (Entrevista a mamá boliviana, noviembre de 2016)

Tanta es la carga negativa que implica ser llamado/a boliviano/a, así como el trato hostil que sufren muchos/as, que la estadía en la escuela puede tornarse insoportable; no se aguanta tanta humillación como a veces se pretende. Tan es así, que en ocasiones los/as estudiantes desean abandonar la escuela. Así, ante los actos de discriminación que sufren, terminan faltando solo unos días, dejan la escuela por un tiempo o la abandonan definitivamente, como en el caso del hijo de Roberta. Quienes continúan en la escuela, ante reiteradas situaciones de discriminación y maltrato (vividas "en carne propia" o presenciadas con respecto a familiares o amigos/as), se niegan a revelar sus orígenes. En muchos casos, este ocultamiento puede ser interpretado como una "estrategia para sobrevivir" (Domenech, 2010) en ciertos contextos que pueden ser hostiles y violentos en su presencia, por considerarlos parte de grupos raciales inferiores. Durante el trabajo de campo esto fue claro en varias situaciones escolares, en las cuales ante el señalamiento y asignación de determinadas identidades, algunos/as estudiantes de la secundaria intentaban desmarcarse:

Geografía, $2^{\circ}$ año de la secundaria. La profesora comienza a repasar la definición de población [...] Inmediatamente pregunta cuántos del aula "no nacieron en el territorio", entonces les pide que levanten la mano. La única que la levanta es Eusebia, el resto se ve dudoso, entonces la profesora comienza a interpelarlos. Le pregunta a Pedro dónde nació. El joven duda, no se lo escucha, dice que no recuerda. Sus compañeros/as comienzan a decir que nació en Bolivia, la profesora pregunta si es así. Él termina diciendo que nació en Perú [...] Los/as estudiantes [...] le dicen a la profesora que no nació en Perú, que es de Bolivia y que está mintiendo. La profesora dice "él es inmigrante, eso es lo que importa" [...] Le pregunta si sabe hablar quechua o alguien en su familia. Contesta que no, que en su casa no hablan. La profesora parece sorprenderse. Uno de los estudiantes le dice que su mamá sí habla quechua porque la vez pasada la escuchó hablar con otra señora. Pedro se ríe nervioso, no dice nada. (Nota de campo, junio 2017)

Al preguntarle a la profesora si no temía señalar o marcar a los/as estudiantes exponiendo frente al resto del curso sus orígenes, su respuesta fue:"no, no me parece. Bah, me parece que no pero no sé. Habría que averiguar si después los discriminan por eso pero hay muchos que son bolivianos [...]". Sin embargo, a pesar de ser 
la mayoría, las situaciones hostiles vividas producto del origen o la condición de migrante existen. Si no existieran, Pedro no tendría que mentir con respecto a su lugar de nacimiento ni el de su familia.

Así, en muchas ocasiones, con el objetivo de valorizar las diferencias, normalizarlas y recuperar las voces de los/as estudiantes, se olvida que tanto dentro de la escuela como fuera de ella existen relaciones de poder y, por ende, de desigualdad en las cuales muchos/as de ellos/as y sus familias se encuentran inmersos/as. Es entonces - cuando la valorización de la diversidad cultural queda descontextualizada de un marco más amplio que el meramente escolarque los/as estudiantes se sienten expuestos y no pueden vivenciar de forma positiva ciertas actividades, preguntas o discursos escolares que se presentan como tales (Taruselli, 2017). De igual manera, en pos de una reivindicación de la diversidad, en varias ocasiones la escuela recorta a los sujetos cristalizando sus identidades con respecto a una única categoría de identificación (García Palacios, 2011). El problema radica en que, además de poner a prueba sus identificaciones e intentar definirlas, como sostiene Novaro (2011), "nombrar al otro no es solo una forma de reconocerlo, sino que también puede ser una forma de marcación en tanto un término (indio, hablante de lengua indígena, boliviano) lleva asociado un significado peyorativo que se impone sobre alguien" (p. 188). Con el término inmigrante sucede lo mismo, ya que este connota un sentido negativo y, por ende, aquellos/as a quienes se los/as nombra así con naturalidad -como vimos- rara vez se definen así mismos/as de esa forma e intentan desmarcarse como tales (García Borrego, 2003).
Julia, la profesora, me cuenta que a principio de año comenzó a venir un estudiante nuevo proveniente de Bolivia. Como en la clase estaban analizando textos incaicos, se le ocurrió que el joven podría traducir alguno al quechua para ver cómo eran originalmente. Así, el estudiante realizó la traducción durante la clase a pedido suyo. Semanas después, Julia se enteró que el joven nuevo dejó la escuela y se volvió a Bolivia porque parece que luego de esa actividad fue cargado por sus compañeros/ as. Ella no lo puede creer ya que durante la actividad no notó ninguna actitud rara del resto de los estudiantes. "No me percaté en que se hayan burlado, a lo mejor algún comentario [...] a lo mejor se ríen pero no sé si se reían por eso o si se reían por otra cosa". (Nota de campo, junio 2017)

Ser boliviano/a en la escuela, ser nombrado/a de ese modo, implica lidiar cotidianamente con la carga valorativa que tiene la figura social del inmigrante boliviano (Domenech, 2014). Esta, además de representar en la actualidad la causa de varias problemáticas que atraviesa el país, se asocia a la figura del indígena construida históricamente por la escuela, en la cual se lo concibe como parte del pasado y portador de una cultura poco evolucionada:

Ciencias sociales, 5 to. grado. Luego de charlar acerca de la conquista de América, la maestra les pregunta a los/as chicos/as: “¿si pudieran regalarle un objeto a un aborigen, qué le regalarían?”. Inmediatamente, agrega que [...] a los aborígenes de la época de Colón, ya que los de ahora no necesitan nada -dando a entender que conocen todo lo que ellos/as conocen. [...] Les propone que piensen algo que les sirva. Los/as chicos/as comienzan a postular sus ideas en voz alta y ella les va contestando: que para qué les van a regalar una calculadora, “¿qué cuenta van a sacar (los aborígenes)?”; que tampoco un plato, ellos no comían con plato y si no, se los hacían ellos mismos. Los chicos entonces piensan alternativas y comienzan a gritar: “un shampoo”, “un jabón en polvo”, “agua yjabón”, “un espejo y un peine”. La maestra se ríe. (Nota de campo, octubre de 2016) 
"[...] yo veo que ellas (sus hijas) no les gusta ser hijos de bolivianos [...] para mí los chicos no quieren ser bolivianos... para mí que tienen... el tema de que... por ahí los bolivianos siempre fuimos pobres, venimos de... de... cómo te puedo decir... pueblos originarios vendríamos a ser, ¿no? Y como ellos estudian la historia... y todos saben que... y siempre se nos hizo creer que éramos, los indios éramos tontos, que no sabíamos organizarnos y todo eso... para mí que viene por ese lado [...] que el indio era malo, que era feo, pero no. [...] (Entrevista a mamá boliviana, diciembre 2017)

Ahora bien, a pesar de que en lo formal se imparte desde el gobierno y las instituciones escolares un nuevo paradigma educativo que problematiza la imagen de "lo indígena" como símbolo de un pasado lejano y bárbaro, continúan discurriéndose, en lo cotidiano, discursos portadores de un estereotipo negativo, según el cual los indígenas son los sucios, los atrasados, los que no saben, los que necesitan siempre algo de Occidente. Pese a las innovaciones, si bien los términos han cambiado (indios, aborígenes, pueblos originarios), las concepciones tradicionales continúan vigentes (Novaro, 2003). En consecuencia, por lo arraigadas que se encuentran estas ideas y por la naturalidad con la que son afirmadas por personas (docentes) e instituciones (escuelas) portadoras de cierto poder y autoridad, terminan siendo incorporadas y reproducidas por los individuos objeto de aquellas. Es así que estos, en ocasiones, incorporan una actitud negativa y de rechazo hacia su propia cultura, a partir de la falsa idea de esta como algo inferior y desagradable (Freire, 1985 en Rebellato, 2010). Esto se observa, por ejemplo, cuando el término boliviano/a es utilizado de forma peyorativa entre los/as mismos/as chicos/as de origen boliviano, cuando intentan desmarcarse ante los señalamientos de otras personas que los/as identifican como tales (aunque también lo podemos asociar a estrategias para evitar situaciones hostiles hacia sus personas), o como cuando "no les gusta ser hijos de bolivianos".

\section{Reflexiones finales}

A pesar de que el sistema escolar, en lo formal, transformó su paradigma de inclusión pasando de una mirada asimilasionista a otra de aceptación y respeto por la diversidad, continúan dándose situaciones que podemos analizar como formas solapadas de marginalización y segregación, aunque en ocasiones suceden de forma explícita y violenta. Esto se da en el marco de una sociedad que continúa pensándose blanca y europea y en la cual los/as inmigrantes de países latinoamericanos, pero sobre todo vecinos, son vistos como grupos raciales inferiores.

Así, a lo largo de este trabajo, analizamos cómo ciertas actitudes (pasivas y activas de asimilación), discursos (nacionalistas, dualistas y estereotipados) y prácticas (discriminatorias y de señalamiento) que se presentan en la escuela influyen de forma negativa en las experiencias escolares de los/as estudiantes de origen boliviano. Muchos/as de ellos/as, atravesados/as por múltiples situaciones que los/as interpelan, ponen a prueba sus construcciones identitarias (así como también las limitan) y los/as ubican en un lugar negativo e inferior con respecto al resto; utilizan diversas estrategias para "sobrevivir" a la cotidianeidad escolar.

En el contexto analizado, dichas estrategias tuvieron que ver con: la desmarcación por medio del ocultamiento de los orígenes o su negación, el abandonando de la lengua y ciertas costumbres propias, y el enfrentamiento muchas veces violento con sus compañeros para defenderse frente a la humillación sufrida. 
En consecuencia, estas experiencias escolares, marcadas por la subordinación, terminan derivando en trayectorias escolares de difícil transcurrir, discontinuas y/o truncas. En otras palabras, cuando las estrategias aplicadas para evitar o superar determinadas situaciones hostiles no funcionan, la solución resulta ser el abandono temporal o definitivo de la escuela.

A partir de la descripción y análisis de estas experiencias escolares, pudimos dar cuenta del hecho de que la sola inclusión y permanencia de los/as niños/ y jóvenes en las instituciones educativas no es beneficiosa per se. En este sentido -sin dejar de lado otras variables y factores externos-, se esclarece la importancia del estudio de aquello que sucede en la escuela para explicar determinados hechos del sistema educativo como lo es la pérdida de matrícula escolar de chicos/as de origen boliviano en el paso de la escuela primaria a la secundaria.

\section{Sobre la autora}

María Eugenia Taruselli es profesora y licenciada en Ciencias Antropológicas. Becaria doctoral de la Universidad de Buenos Aires, radicada en el Instituto de Lingüística de la Facultad de Filosofía y Letras. Ciudad Autónoma de Buenos Aires, Argentina.

Adscripta en la materia Didáctica y Prácticas de la Enseñanza de la Antropología de la FFyL, UBA.

Becaria del proyecto de investigación "Lenguas indígenas del Gran Chaco y zonas adyacentes. Fenómenos gramaticales y prácticas comunicativas en contextos plurilingües". Instituto de Lingüística de la Universidad de Buenos Aires. Ciudad Autónoma de Buenos Aires, Argentina.

Integrante del proyecto de investigación "Interculturalidad y educación en comunidades toba/qom y mbyá-guaraní de Argentina: una aproximación histórico-etnográfica a la diversidad étnica y lingüística en las escuelas". Programa de Antropología y Educación del Instituto de Ciencias Antropológicas. Ciudad Autónoma de Buenos Aires, Argentina.

\section{Financiamiento:}

Este documento es resultado del financiamiento otorgado por el Estado Nacional, por lo tanto queda sujeto al cumplimiento de la Ley № 26.899. La investigación se financia con una Beca Doctoral de la UBA (Resolución 1246/2018), en el marco del Proyecto UBACyT 20020160100106B, “Lenguas indígenas del Gran Chaco y zonas adyacentes. Fenómenos gramaticales y prácticas comunicativas en contextos plurilingües”, radicado en el Instituto de Lingüística de la Facultad de Filosofía y Letras. CABA, Argentina.

\section{Agradecimientos:}

Quisiera agradecer a la Universidad de Buenos Aires por la beca de doctorado que se me otorgó, así como a la Dra. María Cristina Messineo en cuyo proyecto UBACyT se enmarca mi investigación. Asimismo, quiero darle las gracias a mi directora la Dra. Ana Carolina Hecht por sus aportes para este artículo y estar siempre presente. También quiero agradecer a Agustina Taruselli y Rebeca Brayner por su ayuda con las traducciones. Finalmente, quiero hacer el agradecimiento más especial y sentido que es para mi mamá, mi papá y mi compañero, quienes cuidaron a Pedrito para que pueda sentarme a escribir. Gracias a vos también hijito, por tus siestas eternas. 


\section{Q Referencias bibliográficas}

》 Beheran, M. (2008). Migraciones y escolaridad: reflexiones metodológicas en torno al trabajo de campo con niños/as y jóvenes. Trabajo presentado en el I Encuentro Latinoamericano de Metodología de las Ciencias Sociales. La Plata, Argentina.

» Beheran, M. (2012). Migraciones y educación en la argentina. Transformaciones y continuidades. En S. Novick (Dir.), Migración y políticas públicas. Nuevos escenarios y desafíos (pp. 201-226). Buenos Aires: Catálogos.

» Brubaker, R. y Cooper, F. (2005). Más allá de Identidad. En J. Loïc y D. Wacquant (Coords.), Repensarlos Estados Unidos para una sociología del hiperpoder (pp. 178-227). Barcelona: Anthropos.

》 Caggiano, S. (2005). Lo que no entra en el crisol: Inmigración boliviana, comunicación intercultural y procesos identitarios. Buenos Aires: Prometeo.

"Chritensen, P. y Prout, A. (2002). Working with ethical symmetry in social research with children. Sage Journals, 9 (4): 477-497.

" Diez, M. L. (2011). Biografías no autorizadas en el espacio escolar. Reflexiones en torno a ser migrante en la escuela. En G. Novaro (Coord.), Niños indígenas y migrantes. Tensiones identitarias, experiencias formativas y procesos de escolarización (pp. 153-179). Buenos Aires: Biblos.

» Diez, M. L. (2013). Repensando la interculturalidad en educación: aportes de la investigación socioantropológica a un campo problemático. Docencia, 51, 4-16.

»Diez, M. L. y Novaro, G. (2007). Chicos migrantes en situaciones escolares: entre el recuerdo y el olvido, entre la afirmación, la marca y el silenciamiento. Trabajo presentado en las VII Jornadas de Sociología. Facultad de Ciencias Sociales, Universidad de Buenos Aires. Buenos Aires, Argentina.

» Diez, M. L. y Novaro, G. (2012). ¿Una inclusión silenciosa o las sutiles formas de la discriminación? Reflexiones a propósito de la escolarización de niños bolivianos. En C. Courtis y M. I. Pacecca (Comps.), Discriminaciones étnicas y nacionales. Un diagnóstico participativo (pp.37-57). Editores del Puerto y Asociación por los Derechos Civiles.

》Diez, M. L y Novaro, G. (2014). Continuidades y discontinuidades entre sistemas educativos nacionales: la educación en Bolivia y en Argentina desde una perspectiva intercultural. En A. I. Villa y M. E. Martínez (Comps.), Relaciones escolares y diferencias culturales: la educación en perspectiva intercultural (pp. 199-230) Buenos Aires: Noveduc.

»Domenech, E. (2010). Etnicidad e inmigración: ¿Hacia nuevos modos de integración en el espacio escolar? Astrolabio, 1. Recuperado de http://biblioteca.clacso.edu.ar/Argentina/cea-unc/20121212122149/Domenech2.pdf

"Domenech, E. (2014). "Bolivianos" en la "escuela argentina": representaciones acerca de los hijos de inmigrantes bolivianos en una escuela de la periferia urbana. REMHU, 42, 171-188.

" Franzé Mundanó, A. (2002). Lo que sabía no valía. Escuela, diversidad e inmigración. Madrid: Consejo Económico y Social-Comunidad de Madrid.

" García Borrego, I. (2003). Los hijos de inmigrantes extranjeros como objeto de estudio de la sociología. Anduli: revista andaluza de ciencias sociales, 3, 27-46. 
» García Palacios, M. (2011). Religión y etnicidad. Procesos educativos e identificaciones de los niños y niñas de un barrio indígena urbano. En G. Novaro (Comp.), Niños indígenas y migrantes. Tensiones identitarias, experiencias formativas y procesos de escolarización (pp. 65-85) Buenos Aires: Biblos.

» García Palacios, M. y Hecht, A. C. (2010). “Cuando era más chica, no sabía que era toba”. Identificaciones étnicas en las trayectorias de vida de jóvenes de un barrio indígena en Buenos Aires. Trabajo presentado en el Coloquio Internacional Juventud, etnicidad, ruralidad y movimientos translocales en Latinoamérica. Bariloche, Argentina.

» Gavazzo, N. (2013). No soy de aquí, ni soy de allá... Alterización y categorías de identificación en la generación de los hijos de inmigrantes bolivianos y paraguayos en Buenos Aires. Claroscuro, o (12): 1-23.

» Gavazzo, N., Beheran, M. y Novaro, G. (2014). La escolaridad como hito en las biografías de los hijos de bolivianos en Buenos Aires. Revista Interdisciplinar da Mobilidade Humana, 22(42), 189-212.

» Grimson, A. (2006). Nuevas xenofobias, nuevas políticas étnicas en Argentina. En E. Jelin y A. Grimson (Comps.), Migraciones regionales hacia la Argentina (pp. 69-99). Buenos Aires: Prometeo.

» Groisman, L. V. y Hendel, V. (2017). Interpelaciones identitarias y efectivización del derecho a la educación de jóvenes migrantes en contextos escolares de la Argentina. Crítica Educativa, 33), 5-24.

» Hecht, A. C. (2007). Pueblos indígenas y escuela. Políticas homogeneizadoras y políticas focalizadas en la educación argentina. Políticas Educativas, Campinas, 1(1), 183-194.

» Hecht, A. C. (2013). (In)definiciones de la escolarización en contextos de diversidad etnolingüística. Análisis de la EIB en Argentina. Século XXI Revista de Ciências Sociais, 3(1), 185-211.

» Juliano, D. (1987). El discreto encanto de la adscripción étnica voluntaria. En Ringuelet, R. (Comp.), Procesos de contacto interétnico (pp. 83-113). Buenos Aires: Ediciones Búsqueda.

» Kessler, G. (2014). Tendencias contrapuestas en educación, salud y vivienda. En Controversias sobre la desigualdad. Argentina, 2003-2013 (pp. 115-144). Buenos Aires: Fondo de Cultura Económica.

» Martínez, L. (2011). Niños migrantes y procesos de identificación en el contexto escolar: "no se animan a contar". Algunas aproximaciones al análisis de la vergüenza. Revista Latinoamericana de Educación Inclusiva, 6(1), 73-88.

» Mendiburu, I. V., Guitart, M. E. y Badenas, J. O. (2010). Identidad nacional, lengua y escuela. Revista de Educación, 353, 39-65.

» Novaro, G. (2003). “Indios”, “aborígenes” y “pueblos originarios”. Sobre el cambio de conceptos y la continuidad de las concepciones escolares. Educación, lenguaje y sociedad, 1(1), 199-219.

» Novaro, G. (2011): Niños migrantes y escuela: ¿identidades y saberes en disputa? En G. Novaro (Comp.), Niños indígenas y migrantes. Tensiones identitarias, experiencias formativas y procesos de escolarización (pp. 179-203). Buenos Aires: Biblos.

» Novaro, G. (2014). Procesos de identificación nacional en población migrante: continuidades y quiebres en las relaciones intergeneracionales. Revista de Antropología Social, 23, 157-179.

» Novaro, G. (2016). Migración boliviana, discursos civilizatorios y experiencias educativas en Argentina. Revista Nómadas, 45, 105-121. 
"Novaro, G., A. Borton, Diez, M. L. y Hecht, A. C. (2008). Sonidos del silencio, voces silenciadas. Niños indígenas y migrantes en escuelas de Buenos Aires. Revista Mexicana de Investigación Educativa, 13(36), 173-201.

» Rebellato, J. L. (2010). Paulo Freire: educación y proyecto ético-político de transformación. En C. Korol (Comp.), Pedagogía de la resistencia. Cuadernos de Educación Popular (pp. 49-65). Ciudad Autónoma de Buenos Aires: Ediciones Madres de Plaza de MayoAmérica Libre.

" Rivas Flores, J. I., Leita Méndez, A. E., Cortes González, P., Marquez García, M. J. y Padua Arcos, D. (2010). La configuración de identidades en la experiencia escolar. Escenarios, sujetos y regulaciones. Revista de Educación. Universidad de Málaga, 353, 187-209.

》 Rockwell, E. (2009). La experiencia etnográfica. Historia y cultura en los procesos educativos. Buenos Aires: Paidós.

» Sinisi, L. (1999). La relación nosotros-otros en espacios escolares “multiculturales". Estigma, estereotipo, racialización. En M. R. Neufeld y J. A. Thisted (Comps.), De eso no se habla. Los usos de la diversidad sociocultural en la escuela (pp. 189-230). Buenos Aires: EUDEBA.

» Sinisi, L. (2010). Integración o Inclusión escolar: ¿un cambio de paradigma? Boletín de Antropología y Educación, 1, 11-14.

"Szulc, A., Hecht, A. C., Hernández, M. C., Laevy, P., Varela, M., Verón, L., Enriz, N. y Hellemeyer, M. (2009). La investigación etnográfica sobre y con niños y niñas. Una mirada desde la antropología. Trabajo presentado en el XXVII Congreso de la Asociación Latinoamericana de Sociología. Buenos Aires, Argentina.

" Taruselli, M. E. (2017). Reflexiones en torno al tratamiento de la diversidad cultural en escuelas rurales del Conurbano Bonaerense. Papeles de Trabajo-Centro de Estudios Interdisciplinarios en Etnolingüística y Antropología Socio-Cultural, 34, 92-106.

»Taruselli, M. E. (2018). Construcciones identitarias de niños, niñas y adolescentes de origen boliviano durante sus trayectos escolares. Cuadernos del Instituto Nacional de Antropología y Pensamiento Latinoamericano, 27(1), 81-98.

" Terigi, F. (2010). Las cronologías de aprendizaje: un concepto para pensar las trayectorias escolares. Conferencia en Jornada de apertura Ciclo Lectivo 2010. Santa Rosa, La Pampa, Argentina.

》Thisted, S. (2014). Políticas, retóricas y prácticas educativas en torno a la cuestión de las "diferencias". Itinerarios de un siglo largo en el tratamiento de la cuestión de migrantes e indígenas. En A. I. Villa y M. E. Martínez (Comps.), Relaciones escolares y diferencias culturales: la educación en perspectiva intercultural (pp. 133-170). Buenos Aires: Noveduc.

\section{Otras fuentes consultadas}

" Ley de Educación Nº 1420 de 1884

» Ley de Educación Nacional N²6.206 de 2006

》 Ley de Educación de la Provincia de Buenos Aires № 13.688 de 2007

» Ley № 25.871 de 2003

"Decreto de Necesidad y Urgencia N.ำ 70/2017 